\title{
Objective and subjective assessments of nasal obstruction in children and adolescents with allergic rhinitis
}

\author{
Aline I. S. Mendes, ${ }^{1}$ Gustavo F. Wandalsen, ${ }^{2}$ Dirceu Solé ${ }^{3}$
}

\begin{abstract}
Objective: To correlate objective assessment of nasal obstruction, as measured by acoustic rhinometry (volume of the first $5 \mathrm{~cm}$ of the nasal cavity) and active anterior rhinomanometry (total nasal airway resistance), with its subjective evaluation (obstruction scores).

Method: Thirty patients, aged 7 to 18 years, with persistent allergic rhinitis and thirty controls were enrolled. The obstruction score was reported for the whole nasal cavity and for each nostril separately. The three variables were measured at baseline and after induction of nasal obstruction.

Results: There were significant and negative correlations between resistance and nasal volume in all groups and scenarios, except for the most obstructed nostril, in the control group, post-obstruction. For the whole nasal cavity, there was no significant correlation between objective and subjective variables except between score and total nasal cavity volume in the control group, post-obstruction. Regarding the most obstructed nostril, we found a significant negative correlation between score and resistance and a significant positive correlation between score and volume for the total group at baseline. There were no clear differences in the correlation coefficients found in patients and controls. The correlation coefficients did not change after induction of nasal obstruction.

Conclusions: Objective assessment of nasal obstruction did not correlate significantly with subjective evaluation for the nasal cavity as a whole, but there was a correlation for unilateral assessments. There was correlation between the objective evaluations. Allergic rhinitis and acute induction of nasal obstruction did not affect the correlation between objective and subjective assessments of nasal obstruction. Addition of an objective method for evaluation of nasal obstruction could be useful in the research setting; if no such method can be used, each nostril should be evaluated separately.
\end{abstract}

J Pediatr (Rio J). 2012;88(5):389-95: Perennial allergic rhinitis, symptom score, nasal obstruction.

\section{Introduction}

Nasal obstruction is characterized by objective restriction of airflow through the nasal cavity, ${ }^{1}$ which occurs in the setting of increased nasal airflow resistance (NAR). ${ }^{2}$ It is the most bothersome symptom of allergic rhinitis. ${ }^{3-9}$

Nasal patency can be assessed by objective or subjective measurements. Objective measurements include active anterior rhinomanometry (AAR), which consists of simultaneous assessment, during normal breathing, pressure and flow within the nasal cavity, enabling calculation of NAR. ${ }^{4}$ Acoustic rhinometry (AR), another objective method, is based on the emission of sound waves within the nose; when reflected, these waves are picked up by a microphone and electronically analyzed to enable mapping of the nasal anatomy and measurement of nasal cavity volume at different points. ${ }^{4,10}$ Subjective assessment of nasal patency usually employs nasal obstruction scores,

1. MSc in Sciences. Universidade Federal de São Paulo - Escola Paulista de Medicina (UNIFESP-EPM), São Paulo, SP, Brazil

2. Adjunct professor. Disciplina de Alergia, Imunologia Clínica e Reumatologia, UNIFESP-EPM, São Paulo, SP, Brazil.

3. Full tenured professor. Disciplina de Alergia, Imunologia Clínica e Reumatologia, Departamento de Pediatria, UNIFESP-EPM, São Paulo, SP, Brazil.

No conflicts of interest declared concerning the publication of this article.

Suggested citation: Mendes AI, Wandalsen GF, Solé D. Objective and subjective assessments of nasal obstruction in children and adolescents with allergic rhinitis. J Pediatr (Rio J). 2012;88(5):389-95.

Manuscript received Mar 10 2012, accepted for publication Jun 62012.

http://dx.doi.org/10.2223/JPED.2213 
where patients assign a grade or score to their feeling of nasal fullness. ${ }^{11}$

The correlation between subjective perception and objective assessment of nasal obstruction is still highly controversial. Recent evidence has shown that this correlation is usually weak ${ }^{7}$; in most cases, there is disagreement. ${ }^{6,11-15}$ Sometimes, correlations are statistically significant, but not clinically relevant. ${ }^{16}$ Furthermore, most studies have been conducted in adults; there are few such investigations of children and adolescents. $8,17,18$

It is still unclear whether the relationship between perceived nasal fullness and objectively measured nasal obstruction can be affected by the presence of chronic nasal obstruction, by patient age, by variability in the instruments used to measure obstruction, by flare-ups of allergic rhinitis, or by the induction of nasal obstruction.

Despite this wealth of uncertainty, subjective assessment of nasal obstruction has been the main, when not the sole, variable of countless studies on nasal physiology and the foundation for a variety of pharmacological and surgical interventions for patients with allergic rhinitis. ${ }^{5}$ This has introduced the potential for methodological bias in these studies and weakened their results and conclusions.

The objective of this study was to compare objective assessments of nasal obstruction - NAR, as measured by $A A R$, and volume of the first $5 \mathrm{~cm}$ of the nasal cavity (V5), as measured by AR - between themselves and with subjective assessment - expressed as an obstruction score (OS) - to ascertain whether the correlations between objective and subjective variables change over time or under different conditions.

\section{Methods}

The study sample comprised 36 children and adolescents with allergic rhinitis, aged 7 to 18 years, who were enrolled for regular follow-up at the outpatient Allergy and Clinical Immunology clinic of the Department of Pediatrics, Universidade Federal de São Paulo, Escola Paulista de Medicina (UNIFESP-EPM). All had a diagnosis of moderate to severe persistent allergic rhinitis of at least 12 months' duration, according to Allergic Rhinitis and its Impact on Asthma initiative criteria ${ }^{19}$ and immediate skin-test reactivity (mean wheal diameter $\geq 3 \mathrm{~mm}$ ) 20 to at least one inhaled allergen (Dermatophagoides pteronyssinus, D. farinae, Blomia tropicalis, dog epithelia, cat epithelia, Periplaneta americana, Blattella germanica, mixed fungi, mixed pollen [IPI-ASAC, Brazil]).

The control group consisted of 34 children and adolescents in the same age range with no clinical history of allergic rhinitis or atopy, no significant nasal cavity changes on anterior rhinoscopy, and no skin-test reactivity to the same battery of inhaled allergens.
In both groups, children were excluded if they had significant anatomical defects of the upper airway, such as septum deviation, adenoid hypertrophy, or nasal polyps; a history of systemic or (nasal) topical corticosteroid use in the 30 days preceding the study; or a history of upper airway infection in the 30 days preceding the study. Antihistamines and any other medications were discontinued at least 10 days prior to study enrollment. Patients with complete obstruction of one or both nostrils were excluded from the sample due to the impossibility of performing AAR in this setting.

\section{Assessment of nasal function}

Objective assessment of nasal patency consisted of consecutive and alternated use of AAR (for total calculation of NAR) and AR (for calculation of V5) (Rhinometrics A/S, Lynge, Denmark), performed according to usual recommendations. ${ }^{21}$ One person performed all measurements, which were obtained in triplicate, and measurements were only accepted when the intra-rater variation coefficient was $<10 \%$. During examinations, a second investigator observed all procedures to prevent error. Neither of the investigators was blinded.

For subjective assessment, patients assigned a score of zero to 10 to their feelings of nasal fullness in both nostrils and in each nostril separately, after intranasal histamine administration. Zero corresponded to severe obstruction and 10 , to a completely unobstructed nostril.

\section{Histamine nasal provocation test}

After 20 minutes of acclimatization, baseline V5, NAR, and OS measurements were obtained. To start the nasal provocation test (NPT), 3 minutes after baseline measurements, $0.15 \mathrm{~mL}$ of normal saline solution $(\mathrm{NaCl}$ $0.9 \%$ ) were instilled into each nostril. New measurements were then obtained and used as a reference for assessment of response. Finally, $0.15-\mathrm{mL}$ aliquots of preservative-free, room-temperature, isotonic solutions containing graded doses of histamine dihydrochloride $(0.12,0.25,0.5,1.0$, 2.0, 4.0, and $8.0 \mathrm{mg} / \mathrm{mL}$; IPI-ASAC, Brazil) were sprayed into each nostril, with a 10-minute interval between puffs. V5, NAR, and OS were measured 5 minutes after each application. The NPT was considered positive and thus terminated as soon as NAR was found to have increased by at least $100 \% .22,23$

This study was approved by the UNIFESP-EPM Research Ethics Committee (study protocol \#1041/10), and the parents or legal guardians of all subjects provided written informed consent for participation prior to any study procedures.

\section{Statistical analysis}

Sample size calculation, taking into account the mean correlation coefficient of 0.5 between objective and subjective 
measurements, $8,15,24,25$ showed that at least 29 subjects in each group were required for a statistical power of $80 \%$ $(\beta=0.2)$ and a significance level of $5 \%(\alpha=0.05)$.

The nonparametric Mann-Whitney $U$ test was used for between-group comparison of results, and Spearman's rank correlation coefficient for evaluation of the relationships between variables. All statistical procedures were performed in the SPSS 17.0 software environment. In all analyses, the null hypothesis was rejected at the $5 \%$ level.

To enable comparison of subjects by age, the study groups were divided into age-based quartiles and the subjects from the first and third quartiles (25th and 75th percentiles) were considered for analysis.

\section{Results}

Of the 36 patients with allergic rhinitis, two were excluded because they could not understand the concept of a score, one for failure to cooperate, and three for complete obstruction of one or both nostrils, which makes AAR infeasible.

Of the 34 children and adolescents in the control group, 30 underwent acceptable assessments. Two were excluded due to technical difficulties during the NPT and two others due to acute upper respiratory tract infection. Therefore, the final sample comprised 30 subjects in each group.
Mean age was $13.1 \pm 3.3$ years in the allergic rhinitis group and $14 \pm 3.2$ years in the control group (no significant between-group difference). There was a slight female predominance in both groups ( $60 \%$ of subjects in the rhinitis group and $63 \%$ of controls).

There were no severe adverse reactions during NPT. One asthmatic patient in the rhinitis group developed bronchospasm at the end of the test, which resolved promptly with administration of inhaled salbutamol.

At baseline (start of NPT), patients in the allergic rhinitis group had significantly higher NAR values than controls $\left(0.309 \mathrm{~Pa} / \mathrm{cm}^{3} / \mathrm{s}\right.$ vs. $0.205 \mathrm{~Pa} / \mathrm{cm}^{3} / \mathrm{s}$ respectively), lower V5 values ( 8.6 vs. $9.6 \mathrm{~cm}^{3}$ respectively), and no difference in total OS (8.3 vs. 8.7 points respectively). Assessment of each nostril separately - that is, most obstructed and least obstructed - showed significant between-group differences in some of the variables of interest (Table 1). Overall nasal cavity values and individual values for the most obstructed nostril were consistently different from those of subjects in the control group. These differences were less evident after NPT. A summary of the correlations between OS and objective measurements (NAR, V5) the allergic rhinitis and control groups and in the sample as a whole is shown in Table 2.

Assessment of Spearman's rank correlation coefficients for the whole sample, allergic per night is group, and

Table 1 - Mean nasal airflow resistance $\left(\mathrm{Pa} / \mathrm{cm}^{3} / \mathrm{s}\right)$, volume of the first $5 \mathrm{~cm}$ of the nasal cavity $\left(\mathrm{cm}^{3}\right)$, and nasal obstruction scores at baseline and after nasal provocation testing, for the nasal cavity as a whole, most obstructed nostril, and least obstructed nostril

\begin{tabular}{|c|c|c|c|c|c|c|}
\hline \multirow[b]{2}{*}{ Variable } & \multicolumn{3}{|c|}{ Baseline } & \multicolumn{3}{|c|}{ Post-NPT } \\
\hline & $\begin{array}{l}\text { Allergic rhinitis } \\
\qquad(\mathrm{n}=\mathbf{3 0})\end{array}$ & $\begin{array}{l}\text { Control } \\
(n=30)\end{array}$ & $\mathbf{p}$ & $\begin{array}{l}\text { Allergic rhinitis } \\
\qquad(\mathrm{n}=\mathbf{3 0})\end{array}$ & $\begin{array}{l}\text { Control } \\
(n=30)\end{array}$ & $\mathbf{p}$ \\
\hline \multicolumn{7}{|l|}{ NAR } \\
\hline Whole nasal cavity & $0.309^{*}$ & 0.205 & 0.047 & 0.697 & 0.461 & 0.053 \\
\hline Most obstructed nostril & $1.038^{*}$ & 0.543 & 0.020 & 5.228 & 6.190 & 0.090 \\
\hline Least obstructed nostril & 0.504 & 0.346 & 0.162 & 0.964 & 0.621 & 0.101 \\
\hline \multicolumn{7}{|l|}{ V5 } \\
\hline Whole nasal cavity & $8.6^{*}$ & 9.6 & 0.045 & 6.5 & 7.1 & 0.135 \\
\hline Most obstructed nostril & $3.8^{*}$ & 4.3 & 0.021 & 2.8 & 3.1 & 0.162 \\
\hline Least obstructed nostril & 4.9 & 5.3 & 0.141 & 3.7 & 4.0 & 0.156 \\
\hline \multicolumn{7}{|l|}{ os } \\
\hline Whole nasal cavity & 8.3 & 8.7 & 0.472 & 6.6 & 6.7 & 0.781 \\
\hline Most obstructed nostril & $6.2^{*}$ & 7.9 & 0.018 & $4.0^{*}$ & 5.4 & 0.017 \\
\hline Least obstructed nostril & 8.4 & 8.6 & 0.806 & 7.3 & 7.2 & 0.982 \\
\hline
\end{tabular}

$\mathrm{NAR}=$ nasal airflow resistance; NPT = nasal provocation testing; OS = obstruction score; V 5 = volume of the first $5 \mathrm{~cm}$ of the nasal cavity. ${ }^{*} p \leq 0.05$. 
Table 2 - Comparison between obstruction scores, nasal airflow resistance $\left(\mathrm{Pa} / \mathrm{cm}^{3} / \mathrm{s}\right)$, and volume of the first $5 \mathrm{~cm}$ of the nasal cavity $\left(\mathrm{cm}^{3}\right)$ in the allergic rhinitis group, control group, and overall sample, at baseline and after nasal provocation testing

\begin{tabular}{|c|c|c|c|c|c|c|}
\hline \multirow[b]{2}{*}{ Comparison } & \multicolumn{2}{|c|}{ Whole nasal cavity } & \multicolumn{2}{|c|}{ Most obstructed nostril } & \multicolumn{2}{|c|}{ Least obstructed nostri } \\
\hline & $\mathbf{r}^{*}$ & $\mathbf{p}$ & $\mathbf{r}^{*}$ & $\mathbf{p}$ & $\mathbf{r}^{\neq}$ & $\mathbf{p}$ \\
\hline \multicolumn{7}{|c|}{ Rhinitis group, baseline $(n=30)$} \\
\hline OS vs. NAR & -0.025 & 0.45 & $-0.440^{*}$ & 0.01 & 0.005 & 0.49 \\
\hline OS vs. v5 & 0.003 & 0.49 & 0.303 & 0.05 & -0.118 & 0.27 \\
\hline V5 vs. NAR & $-0.587^{\dagger}$ & $<0.001$ & $-0.727^{+}$ & $<0.001$ & $-0.381^{*}$ & 0.02 \\
\hline \multicolumn{7}{|c|}{ Rhinitis group, post-NPT $(n=30)$} \\
\hline OS vs. NAR & 0.236 & 0.10 & $-0.323^{*}$ & 0.04 & 0.068 & 0.36 \\
\hline OS vs. V5 & -0.061 & 0.37 & 0.132 & 0.24 & -0.249 & 0.09 \\
\hline V5 vs. NAR & $-0.477^{+}$ & $<0.001$ & $-0.647^{+}$ & $<0.001$ & $-0.405^{*}$ & 0.01 \\
\hline \multicolumn{7}{|c|}{ Control group, baseline $(n=30)$} \\
\hline OS vs. NAR & -0.140 & 0.23 & $-0.535^{+}$ & $<0.001$ & 0.057 & 0.38 \\
\hline OS vs. V5 & 0.258 & 0.08 & 0.280 & 0.07 & 0.203 & 0.14 \\
\hline V5 vs. NAR & $-0.384^{*}$ & 0.02 & $-0.331^{*}$ & 0.04 & $-0.316^{*}$ & 0.04 \\
\hline \multicolumn{7}{|c|}{ Control group, post-NPT $(n=30)$} \\
\hline OS vs. NAR & 0.009 & 0.48 & -0.162 & 0.20 & 0.070 & 0.36 \\
\hline OS vs. v5 & $-0.309^{*}$ & 0.05 & $-0.329^{*}$ & 0.04 & -0.223 & 0.12 \\
\hline V5 vs. NAR & $-0.383^{*}$ & 0.02 & -0.108 & 0.29 & $-0.331^{*}$ & 0.04 \\
\hline \multicolumn{7}{|c|}{ Overall sample, baseline $(n=30)$} \\
\hline OS vs. NAR & -0.071 & 0.29 & $-0.510^{+}$ & $<0.001$ & 0.019 & 0.44 \\
\hline OS vs. v5 & 0.130 & 0.16 & $0.299^{*}$ & 0.01 & 0.016 & 0.45 \\
\hline V5 vs. NAR & $-0.521^{+}$ & $<0.001$ & $-0.569^{+}$ & $<0.001$ & $-0.356^{+}$ & $<0.001$ \\
\hline \multicolumn{7}{|c|}{ Overall sample, post-NPT $(n=30)$} \\
\hline OS vs. NAR & 0.147 & 0.13 & $-0.261^{*}$ & 0.02 & 0.098 & 0.23 \\
\hline OS vs. V5 & -0.180 & 0.09 & -0.041 & 0.38 & $-0.240^{*}$ & 0.03 \\
\hline V5 vs. NAR & $-0.463^{\dagger}$ & $<0.001$ & $-0.417^{+}$ & $<0.001$ & $-0.375^{\dagger}$ & $<0.001$ \\
\hline
\end{tabular}

NAR = nasal airflow resistance; NPT = nasal provocation testing; OS = obstruction score; V5 = volume of the first $5 \mathrm{~cm}$ of the nasal cavity.

* $\mathrm{p} \leq 0.05$.

$\dagger \mathrm{p} \leq 0.001$

‡ Spearman.

control group, stratified by age (10 years or younger and 17 years or older) (Table 3 ), showed that, for the overall sample ( $n=60)$, the correlations found in the youngest age range ( $n=12$ ), were similar to those observed in the group as a whole, namely, a significant, negative correlation between NAR and V5 when the whole nasal cavity was considered ( $r=-0.75)$. When only the most obstructed nostril was considered, there were significant, negative correlations between OS and NAR $(r=-0.59)$ and between NAR and V5 $(r=-0.64)$. All variables behaved similarly after NPT. In older patients $(n=12)$, however, none of the aforementioned correlations were significant at baseline, and the only significant correlations were a negative correlation between NAR and V5 $(r=-0.59)$ and a positive correlation between OS and V5 $(r=0.51)$, both in the least obstructed nostril.

Findings in the rhinitis group $(\mathrm{n}=30)$ were similar to those of the age-stratified sample as a whole. Among the youngest subjects ( $n=8)$, there were no significant correlations between the objective variables (NAR/V5) or between the objective and subjective measurements (OS/ NAR and OS/V5) after NPT. Again, no significant correlations were detected among the oldest subjects $(n=8)$.

\section{Discussion}

In this study, there were significant correlations between the two methods used for objective assessment of nasal obstruction across all groups and settings. Conversely, there were no such correlations between objective and subjective measurements when the nasal cavity was assessed as a whole. However, when each nostril was assessed individually, there was a significant negative correlation between OS and NAR and a significant positive correlation between OS and V5. Patient age had no effect on these results. Several factors may explain this disagreement between assessments. 
Objective and subjective assessment appear to evaluate different parameters that are not directly related. ${ }^{13}$ The feeling of nasal fullness is not appear to be determined exclusively by the patent size of the nasal cavity, ${ }^{2,26}$ and may be influenced by anatomical variation, a variety of local stimuli, the chronic nature of nasal obstruction, and even by variability in the instrument used to measure nasal obstruction.

Table 3 - Comparison between obstruction scores, nasal airflow resistance $\left(\mathrm{Pa} / \mathrm{cm}^{3} / \mathrm{s}\right)$, and volume of the first $5 \mathrm{~cm}$ of the nasal cavity $\left(\mathrm{cm}^{3}\right)$ in the allergic rhinitis group, control group, and overall sample, at baseline and after nasal provocation testing, stratified by age range

\begin{tabular}{|c|c|c|c|c|c|c|}
\hline \multirow[b]{2}{*}{ Comparison } & \multicolumn{2}{|c|}{$\begin{array}{c}\text { Whole nasal } \\
\text { cavity }\end{array}$} & \multicolumn{2}{|c|}{$\begin{array}{c}\text { Most obstructed } \\
\text { nostril }\end{array}$} & \multicolumn{2}{|c|}{$\begin{array}{c}\text { Least obstructed } \\
\text { nostril }\end{array}$} \\
\hline & $\mathbf{r}^{*}$ & $\mathbf{p}$ & $\mathbf{r}^{\neq}$ & $\mathbf{p}$ & $\mathbf{r}^{\neq}$ & $\mathbf{p}$ \\
\hline \multicolumn{7}{|c|}{ Allergic rhinitis group, age $\leq 10$ years, baseline $(n=8)$} \\
\hline OS vS. NAR & 0.146 & 0.365 & $-0.685^{*}$ & 0.030 & 0.122 & 0.387 \\
\hline OS vs. V5 & -0.466 & 0.122 & 0.558 & 0.075 & -0.447 & 0.133 \\
\hline V5 vs. NAR & $-0.838^{*}$ & 0.005 & $-0.881^{*}$ & 0.002 & $-0.850^{*}$ & 0.004 \\
\hline \multicolumn{7}{|c|}{ Allergic rhinitis group, age $\leq 10$ years, post-NPT $(n=8)$} \\
\hline OS vs. NAR & 0.405 & 0.160 & -0.410 & 0.157 & -0.038 & 0.464 \\
\hline OS vs. V5 & -0.589 & 0.062 & 0.024 & 0.477 & -0.292 & 0.242 \\
\hline V5 vs. NAR & $-0.929^{+}$ & $<0.001$ & -0.524 & 0.091 & $-0.857^{*}$ & 0.003 \\
\hline \multicolumn{7}{|c|}{ Allergic rhinitis group, age $\geq 17$ years, baseline $(n=8)$} \\
\hline OS vs. NAR & 0.417 & 0.152 & 0.110 & 0.398 & 0.339 & 0.205 \\
\hline OS vs. V5 & 0.049 & 0.454 & -0.121 & 0.387 & 0.594 & 0.060 \\
\hline V5 vs. NAR & -0.405 & 0.160 & -0.551 & 0.079 & -0.024 & 0.478 \\
\hline \multicolumn{7}{|c|}{ Allergic rhinitis group, age $\geq 17$ years, post-NPT $(n=8)$} \\
\hline OS vS. NAR & 0.381 & 0.176 & 0.109 & 0.399 & $-0.630^{*}$ & 0.047 \\
\hline OS vs. V5 & 0.043 & 0.460 & 0.194 & 0.323 & 0.307 & 0.230 \\
\hline V5 vs. NAR & 0.335 & 0.208 & -0.619 & 0.051 & 0.084 & 0.422 \\
\hline \multicolumn{7}{|c|}{ Control group, age $\leq 11$ years, baseline $(n=7)$} \\
\hline OS vs. NAR & 0.468 & 0.145 & -0.482 & 0.137 & 0.243 & 0.300 \\
\hline OS vs. V5 & $-0.748^{*}$ & 0.026 & -0.259 & 0.287 & -0.187 & 0.344 \\
\hline V5 vs. NAR & -0.500 & 0.127 & -0.393 & 0.192 & -0.571 & 0.090 \\
\hline \multicolumn{7}{|c|}{ Control group, age $\leq 11$ years, post-NPT $(n=7)$} \\
\hline OS vs. NAR & 0.315 & 0.246 & $-0.937+$ & 0.001 & 0.412 & 0.179 \\
\hline OS vs. V5 & -0.217 & 0.320 & 0.108 & 0.409 & -0.356 & 0.217 \\
\hline V5 vs. NAR & $-0.821^{*}$ & 0.012 & -0.357 & 0.216 & -0.429 & 0.169 \\
\hline \multicolumn{7}{|c|}{ Control group, age $\geq 17$ years, baseline $(n=6)$} \\
\hline OS vs. NAR & -0.207 & 0.347 & -0.098 & 0.427 & 0.564 & 0.122 \\
\hline OS vs. V5 & $0.828^{*}$ & 0.021 & 0.683 & 0.067 & 0.309 & 0.276 \\
\hline V5 vs. NAR & $-0.714^{*}$ & 0.055 & -0.600 & 0.104 & -0.174 & 0.371 \\
\hline \multicolumn{7}{|c|}{ Control group, age $\geq 17$ years, post-NPT $(n=6)$} \\
\hline OS vs. NAR & 0.001 & 0.500 & -0.213 & 0.343 & 0.679 & 0.069 \\
\hline OS vs. V5 & $0.956^{+}$ & 0.001 & 0.334 & 0.259 & $0.926^{*}$ & 0.004 \\
\hline V5 vs. NAR & -0.086 & 0.436 & -0.543 & 0.133 & 0.543 & 0.133 \\
\hline \multicolumn{7}{|c|}{ Overall sample, age $\leq 10$ years, baseline $(n=12)$} \\
\hline OS vs. NAR & 0.101 & 0.377 & $-0.599^{*}$ & 0.020 & 0.174 & 0.294 \\
\hline OS vs. V5 & -0.401 & 0.098 & 0.210 & 0.256 & $-0.618^{*}$ & 0.016 \\
\hline V5 vs. NAR & $-0.757^{*}$ & 0.002 & $-0.643^{*}$ & 0.012 & $-0.772^{*}$ & 0.002 \\
\hline \multicolumn{7}{|c|}{ Overall sample, age $\leq 10$ years, post-NPT $(n=12)$} \\
\hline OS vs. NAR & 0.253 & 0.214 & $-0.554^{*}$ & 0.031 & 0.280 & 0.189 \\
\hline OS vs. V5 & -0.491 & 0.052 & 0.071 & 0.414 & -0.381 & 0.111 \\
\hline V5 vs. NAR & $-0.762^{*}$ & 0.002 & -0.413 & 0.091 & $-0.713^{*}$ & 0.005 \\
\hline \multicolumn{7}{|c|}{ Overall sample, age $\geq 17$ years, baseline $(n=12)$} \\
\hline OS vs. NAR & 0.331 & 0.146 & 0.331 & 0.147 & 0.435 & 0.079 \\
\hline OS vs. V5 & 0.331 & 0.146 & 0.320 & 0.156 & 0.333 & 0.145 \\
\hline V5 vs. NAR & -0.273 & 0.196 & -0.420 & 0.087 & -0.028 & 0.465 \\
\hline \multicolumn{7}{|c|}{ Overall sample, age $\geq 17$ years, post-NPT $(n=12)$} \\
\hline OS vs. NAR & 0.142 & 0.330 & 0.079 & 0.404 & 0.044 & 0.445 \\
\hline OS vs. V5 & $0.548^{*}$ & 0.032 & 0.401 & 0.098 & $0.511^{*}$ & 0.045 \\
\hline V5 vs. NAR & 0.189 & 0.278 & -0.343 & 0.137 & $-0.594^{*}$ & 0.021 \\
\hline
\end{tabular}

$\mathrm{NAR}=$ nasal airflow resistance; NPT = nasal provocation testing; OS = obstruction score; V 5 = volume of the first $5 \mathrm{~cm}$ of the nasal cavity. ${ }^{*} p \leq 0.05$.

$\dagger \mathrm{p} \leq 0.001$.

‡ Spearman. 
There is still no conclusive evidence as to which area of the nasal cavity is most important to perceived airflow. Evidence suggests that this feeling is mediated by the trigeminal nerve, via a series of receptors distributed uniformly across the nasal vestibule and nasal mucosa.13,27 Edema or inflammation around nerve endings, exercise, exposure to cold air, and alcohol intake may impair nerve function and trigger the feeling of nasal obstruction. Conversely, changes in the ostiomeatal complex due to changes in mucosal edema, soft palate position, and nostril shape may have an impact on NAR without producing any effect on perceived nasal obstruction. ${ }^{2,12}$ Other findings suggest that receptors located in the nasal vestibules (anterior portion of the nares) may be responsible for signaling the feeling of nasal patency, whereas receptors in the nasal cavity would signal the feeling of nasal obstruction. Total inferior turbinectomy may produce marked improvement in perceived nasal obstruction, but with the same reduction in NAR observed after removal of the anterior portion alone. ${ }^{28}$ This is most likely due to the fact that radical turbinectomy entails substantial denervation of the nasal cavity, and this removes receptors involved in the conduction of afferent nerve impulses important to the perception of nasal obstruction. Patients with high NAR exhibit stronger correlations between objective and subjective measurements than patients with low airflow resistance, which implies that patients with obstruction of one or both nostrils would be better able to detect minor changes in airflow than patients with a lesser degree of obstruction. ${ }^{5}$ Conversely, chronically obstructed patients might grow accustomed to nasal fullness and thus minimize its severity. ${ }^{29}$

In this study, correlations between patients in the rhinitis group - that is, those subjected to chronic obstruction - were no stronger than those in the control group. However, patients with complete nasal obstruction could not be assessed in this study due to the impossibility of rhinomanometry. There was also no difference in correlations when patients were subjected to acute nasal obstruction (post-NPT).

André et al. showed that poor nasal patency may occur with high or low airflow resistance, depending on the presence or absence of irregularities in the shape of the nasal cavity. ${ }^{9}$ Priftis et al. showed that, in a sample of preschoolers with allergic rhinitis, there is a wide distribution of NAR values for the same degree of obstruction (asymptomatic, mild, moderate, or severe). ${ }^{8}$

Another source of disagreement was reported by Fairley et al., who showed that subjective parameters are strongly correlated when measurements are obtained repeatedly from the same individual, with each subject being his or her own "calibration curve." Receptors in the nasal mucosa and vestibule are probably involved, but the anatomical site of the "calibration curve" is still unknown. ${ }^{11}$

The use of assessment scales can lead patients to responses due to the scale design itself or to the instructions provided. Scales with too many options may be associated with poorer correlations, and there is a strong correlation between objective assessments of nasal patency and nasal obstruction scores when the latter are scored on a scale of 0 to 3 as opposed to an analog scale of 0 to 10. Fewer subjective score options might increase the correlation between objective and subjective measurements. ${ }^{17}$ As this was a pediatric study, the decision was made to use a scale of 0 to 10 , as the scoring system would be familiar to children as the one used for their school grades.

Studies have reported that children may be more accepting of mouth-breathing than adolescents ${ }^{17}$ and might grow accustomed to chronic nasal obstruction to the point where they no longer considered an issue. During assessment, children might also be influenced by the perceptions of their parents or guardians, which could further distort the correlation between objective and subjective measurements. In the present study, older subjects did not appear able to assess their nasal obstruction more accurately than their younger counterparts; this is consistent with the findings of other authors. ${ }^{7}$ However, the study sample was small when divided by age, which may limit any conclusions.

Separate analysis of each nostril (unilateral assessment) revealed stronger coefficients of correlation then combined analysis of the nasal cavity as a whole. This was easily demonstrated by the absence of significant differences in obstruction scores between the rhinitis and control groups when the phone nasal cavity was assessed, whereas significant between-group differences were present when each nostril was assessed individually (Table 1 ).

The findings of the study are corroborated by a systematic review ${ }^{9}$ that confirmed stronger correlations in the presence of nasal obstruction and when assessment is unilateral, as observed by other authors as well.28,30 The absence of correlation between objective and subjective measurements when the nasal cavity is considered as a whole may be explained by the fact that bilateral assessment does not take into account that obstructionrelated variables originate from separate stimuli provided by paired organs. ${ }^{15}$ If one of the patient's nostrils is more severely obstructed than the other, the patient may report an overall nasal obstruction score that is in fact based on the obstruction of one nostril, which may distort study results. ${ }^{5}$

The gold standard for assessment of nasal obstruction has yet to be established. The introduction of an objective measurement method to clinical practice could contribute to better decision-making. Nevertheless, subjective assessment is still important, as it reflects patient symptoms and quality of life - key factors that lead patients to seek care. Instruments for assessment of patient satisfaction are thus essential to many aspects of diagnosis. Although objective anatomical findings play a critical role in clinical evaluation, 
from the patient's standpoint, the impact of the disease on quality of life may be the most important outcome to assess after treatment ${ }^{14}$; hence the need for combined assessment with different instruments that reflect the multidimensional nature of the feeling of nasal fullness.

Despite these uncertainties, subjective assessment of nasal obstruction has been the main, if not the sole, variable of countless studies on nasal physiology and the foundation for a variety of pharmacological and surgical interventions for patients with allergic rhinitis. This has introduced the potential for methodological bias in these studies and weakened their results and conclusions.

In short, this study demonstrated that objective assessments of nasal obstruction using acoustic AR and AAR did not correlate significantly with subjective assessment of nasal obstruction, as expressed by a selfassigned OS. This correlation held in the presence of nasal disease and after induction of acute nasal obstruction, but improved when each nostril was assessed individually as compared to assessment of the nasal cavity is a whole. Patient age did not seem to interfere with the degree of correlation between objective and subjective assessment of nasal obstruction.

\section{References}

1. van Spronsen $\mathrm{E}$, Ingels KJ, Jansen AH, Graamans K, Fokkens WJ. Evidence-based recommendations regarding the differential diagnosis and assessment of nasal congestion: using the new GRADE system. Allergy. 2008;63(7):820-33.

2. Nathan RA, Eccles R, Howarth PH, Steinsvåg SK, Togias A. Objective monitoring of nasal patency and nasal physiology in rhinitis. J Allergy Clin Immunol. 2005;115(3 Suppl 1):S442-59.

3. Bousquet J, Khaltaev N, Cruz AA, Denburg J, Fokkens WJ, Togias A, et al. Allergic Rhinitis and its Impact on Asthma (ARIA) 2008 update (in collaboration with the World Health Organization, GA(2) LEN and AllerGen). Allergy. 2008;63 Suppl 86:8-160.

4. Lai VW, Corey JP. The objective assessment of nasal patency. Ear Nose Throat J. 1993;72(6):395-400.

5. Campanha SM, Fontes MJ, Camargos PA, Freire LM. The impact of speech therapy on asthma and allergic rhinitis control in mouth breathing children and adolescents. J Pediatr (Rio J). 2010;86(3):202-8.

6. Yaniv E, Hadar T, Shvero J, Raveh E. Objective and subjective nasal airflow. Am J Otolaryngol. 1997;18(1):29-32.

7. Panagou P, Loukides S, Tsipra S, Syrigou K, Anastasakis C, Kalogeropoulos N. Evaluation of nasal patency: comparison of patient and clinician assessments with rhinomanometry. Acta Otolaryngol. 1998;118(6):847-51.

8. Priftis KN, Drigopoulos K, Sakalidou A, Triga M, Kallis V, Nicolaidou P. Subjective and objective nasal obstruction assessment in children with chronic rhinitis. Int J Pediatr Otorhinolaryngol. 2006;70(3):501-5.

9. André RF, Vuyk HD, Ahmed A, Graamans K, Nolst Trenité GJ. Correlation between subjective and objective evaluation of the nasal airway. A systematic review of the highest level of evidence. Clin Otolaryngol. 2009;34(6):518-25.

10. Hilberg $O$, Jackson AC, Swift DL, Pedersen OF. Acoustic rhinometry: evaluation of nasal cavity geometry by acoustic reflection. J Appl Physiol. 1989;66(1):295-303.
11. Fairley JW, Durham LH, ElI SR. Correlation of subjective sensation of nasal patency with nasal inspiratory peak flow rate. Clin Otolaryngol Allied Sci. 1993;18(1):19-22.

12. Simola M, Malmberg H. Sensation of nasal airflow compared with nasal airway resistance in patients with rhinitis. Clin Otolaryngol Allied Sci. 1997;22(3):260-2.

13. Jones AS, Willatt DJ, Durham LM. Nasal airflow: resistance and sensation. J Laryngol Otol. 1989;103(10):909-11.

14. Stewart MG, Smith TL. Objective versus subjective outcomes assessment in rhinology. Am J Rhinol. 2005;19(5):529-35.

15. Clarke JD, Hopkins ML, Eccles R. Evidence for correlation of objective and subjective measures of nasal airflow in patients with common cold. Clin Otolaryngol. 2005;30(1):35-8.

16. Meltzer EO, Jalowayski AA, Orgel HA, Harris AG. Subjective and objective assessments in patients with seasonal allergic rhinitis: effects of therapy with mometasone furoate nasal spray. J Allergy Clin Immunol. 1998;102(1):39-49.

17. Watson WT, Roberts JR, Becker AB, Gendreau-Reid LF, Simons FE. Nasal patency in children with allergic rhinitis: correlation of objective and subjective assessments. Ann Allergy Asthma Immunol. $1995 ; 74(3): 237-40$.

18. Welch MJ, Meltzer EO, Orgel HA, Kemp JP. Assessment of the correlation of rhinometry with the symptoms and signs of allergic rhinitis in children. Ann Allergy. 1985;55(4):577-9.

19. Bousquet J, Van Cauwenberge P, Khaltaev N; Aria Workshop Group; World Health Organization. Allergic rhinitis and its impact on asthma. J Allergy Clin Immunol. 2001;108(5 Suppl):S147-334.

20. Oppenheimer J, Nelson HS. Skin testing. Ann Allergy Asthma Immunol. 2006;96(2 Suppl 1):S6-12.

21. Clement PA, Gordts F; Standardisation Committee on Objective Assessment of the Nasal Airway, IRS, and ERS. Consensus report on acoustic rhinometry and rhinomanometry. Rhinology. 2005;43(3):169-79.

22. Birchall MA, Henderson JC, Studham JM, Phillips I, Pride NB, Fuller RW. The effect of topical fluticasone propionate on intranasal histamine challenge in subjects with perennial allergic rhinitis. Clin Otolaryngol Allied Sci. 1995;20(3):204-10.

23. Sipilä J, Suonpää J, Laippala P. Sensation of nasal obstruction compared to rhinomanometric results in patients referred for septoplasty. Rhinology. 1994;32(3):141-4.

24. Roithmann R, Cole P, Chapnik J, Barreto SM, Szalai JP, Zamel N. Acoustic rhinometry, rhinomanometry, and the sensation of nasal patency: a correlative study. J Otolaryngol. 1994;23(6):454-8.

25. Selner JC, Koepke JW, Staudenmayer H, Dolen WK, Glover GC, Linzmayer MI, et al. Assessment of nasal patency by rhinoscopic measurement of cross sectional nasal airway area: correlation with subjective nasal symptoms. Ann Allergy. 1991;66(1):43-7.

26. Jones AS, Wight RG, Stevens JC, Beckingham E. The nasal valve: a physiological and clinical study. J Laryngol Otol. 1988;102(12):1089-94.

27. Gordon AS, McCaffrey TV, Kern EB, Pallanch JF. Rhinomanometry for preoperative and postoperative assessment of nasal obstruction. Otolaryngol Head Neck Surg. 1989;101(1):20-6.

28. Clarke JD, Hopkins ML, Eccles R. How good are patients at determining which side of the nose is more obstructed? A study on the limits of discrimination of the subjective assessment of unilateral nasal obstruction. Am J Rhinol. 2006;20(1):20-4.

29. Lam DJ, James KT, Weaver EM. Comparison of anatomic, physiological, and subjective measures of the nasal airway. Am J Rhinol. 2006;20(5):463-70.

30. Hirschberg A, Rezek O. Correlation between objective and subjective assessments of nasal patency. ORL J Otorhinolaryngol Relat Spec. 1998;60(4):206-11.

Correspondence:

Aline Inês S. Mendes

Rua dos Otonis, 719/725, Vila Clementino

CEP 04025-002 - São Paulo, SP - Brazil

Tel.: + 55 (11) 5579.1590

Fax: + 55 (11) 5576.4426

E-mail: alinemendes34@yahoo.com.br 